Logos Universality Mentality Education Novelty, Section: Philosophy and Humanistic Sciences

ISSN: 2284-5976 (print), ISSN: 2284-5976 (electronic)

Covered in: CEEOL, Index Copernicus, Ideas RePEc,

EconPapers, Socionet

\title{
THE CONCEPT OF SECULARISM IN THEOLOGICAL AND POLITICAL PERSPECTIVE
}

\author{
Andrei POPÎRDA
}

DOI: http://dx.doi.org/10.18662/lumenphs.2015.0302.05

Logos Universality Mentality Education Novelty, Section:

Philosophy and Humanistic Sciences, III (2), 57-65

The online version of this article can be found at:

http://lumenjournals.com/philosophy-and-humanistic-sciences/

Published by:

Lumen Publishing House

On behalf of:

Lumen Research Center in Social and Humanistic Sciences 


\title{
The Concept of Secularism in Theological and Political Perspective
}

\section{Andrei POPÎRDA ${ }^{1}$}

\begin{abstract}
In a pluralistic society, the concept of secularism acquired many meanings. Clearly, if we take the term strictly etymological its valences not consistent with the principles of modernity. It is therefore necessary, some critical remarks: Can religious affiliations to speak in public? Wants secularism erasing religion from the public and private sphere to move its decline? Taking into account the importance of the historical development of the nation, religious tradition - that identifies most of the population resulting in distinct rights or privileges with respect to other religions? These interrogations are merely open perspective of the present study: a short history of the concept of secularism, coupled with its erminia in a society that is in constant change.
\end{abstract}

Keywords: laity, secularism, Europe, pluralist society, religions.

1 PhD Student, Faculty of Orthodox Theology „Dumitru Stăniloae”, Alexandru Ioan Cuza University, Iaşi, România, andrei.popirda@gmail.com.

57

Popirda, A. (2015). The Concept of Secularism in Theological and Political Perspective. Logos Universality Mentality Education Novelty, Section: Philosophy and Humanistic Sciences, III (2), 57-65. Doi: http://dx.doi.org/10.18662/lumenphs.2015.0302.05 


\section{Introducere}

Începutul secolului al XXI-lea cunoaşte o puternică preocupare în jurul ideii de laicitate atât în țările laice din punct de vedere istoric, precum Franța sau Turcia, cât şi în alte țări, precum Québec, unde noțiunea a fost introdusă mai târziu în urma dezbaterilor publice. Pluralitatea religioasă a reprezentat principalul context care a obligat statele să găsească facilităţi pentru a atenua discriminările religioase în favoarea păcii sociale. Creşterea modurilor de exprimare publică a apartenenței religioase, a contribuit de asemenea la alimentarea interesului pentru laicitate. Libertate de conştiinţ̧̆ şi libertatea religioasă este considerată a fi moştenită, dobândită, într-un stat de drept, dar fără îndoială ea este una din libertăţile fundamentale de care se leagă numeroase întrebări legate de dezvoltarea şi limitele sale. Doreşte laicitatea ştergerea religiei din spațiul public şi îndreptarea declinului acesteia spre sfera privată? T,inându-se cont de importanța în dezvoltarea istorică a unei națiuni, tradiția religioasă - cu care se identifică majoritatea populației are ca rezultat drepturi sau privilegii distincte în raport cu alte confesiuni? Aceste interogații nu fac altceva decât să deschidă perspectiva prezentului studiu: o istorie lapidară a conceptului de laicitate, dublată de erminia acestuia într-o societate aflată într-o permanentă schimbare.

\section{Delimitări conceptuale: „laicitate”, „laic”, „laicism”}

\section{I.1. Ințelesul şi evoluția termenului de „laicitate”}

Cuvântul laicitate are o dublă geneză etimologică, care ne duce cu gândul la două tipuri de opoziție. Prima, care provine din vocabularul eclesiastic latin de la laicus, care semnifică: „cel care nu a primit hirotonia, un non - preot", diferențiindu-se clericul de laic în cadrul comunității creştine. O altă origine a termenului, mai veche, provine de la cuvântul grec Laos care semnifică popor. Etimologia greacă a avut un rol determinant în definirea termenului de laicitate care a prins contur în a doua jumătate a secolului al XIX-lea. Într-adevăr, de îndată ce apare în dicționare, laicitatea evocă o realitate politică în care statul nu îşi mai i-a legalitatea sa de la Biserică sau de la vreo confesiune religioasă, ci de la suveranitatea poporului. Noțiunea evocă un fel de gândire şi viață politică. Dictionnaire de Lettré propune pentru prima dată în 1877, o definiție a laicității ca: „Statul neutru între religii, tolerant pentru toate cultele” („l'État neutre entre les religions, tolérant pour tous les cultes") (Millot, 2008). 
Pentru că statul exercită această neutralitate şi nu privilegiază nici o religie, el nu poate să se asocieze cu nici una dintre ele. Astfel definiția laicităţii a evoluat rapid pentru a include un alt aspect fundamental, cel de separare între puterea politică şi religioasă (Millot, 2008). In Dictionnaire de pédagogie et d'instruction primaire editat de Fernad Buisson în 1887. Laicitatea constă în faptul unui „Stat neutru între culte, independent de toți clerici, eliberat de orice concepție teologică” („État neutre entre les cultes, indépendant de tous les clergés, dégagé de toute conception théologique”) (Millot, 2008, p. 11). Vom aminti că această definiție apare aproape la o sută de ani de la Revoluția franceză. In ceea ce priveşte apariția termenului de „laicitate”, acesta se leagă de adoptarea legii din 1905 asupra separării Bisericii de Stat în Franţa, care nu a omis termenul de „laicitate”. Acest termen precis a apărut cu ocazia Consiliului general de la Seine, din data de 7 noiembrie 1871. În procesul verbal al acestei sesiuni găsim următoarele: „educație gratuită, obligatorie şi laică” (Millot, 2008, p. 11).

\section{I.2. Etimologia termenului de „laic”}

Din punct de vedere lexical, laic, (venit pe filieră greacă, $\lambda \alpha \ddot{i x o ́ \varsigma}$ adjectiv derivat de la $\lambda \alpha o \dot{s}$ ) ne retrimit la doua câmpuri semantice majore:

A.) Pe de o parte înţelegem ceea ce „este independent de toate confesiunile religioase”, o accepțiune modernă în care vorbim de Stat laic, sau de mediul laic, pentru a arăta absența tuturor referirilor religioase din sistemul politic sau educativ (Lacoste, 2007, pp. 761-762).

B.) Celălalt, un sens specific, care este legat de structura Bisericii. Astfel avem unele izvoare ale canonisticii bizantine care fac referire neutră la persoana „laicului” ca la un „non-preot”, definind, aşadar pe laic prin ceea ce nu are în raport cu clericul înzestrat cu darurile sacramentale şi pastorale. $\mathrm{O}$ alta origine a termenului, mai veche, provine de la cuvântul grec „laos” care semnifică popor (Lacoste, 2007, pp. 761-762). Aşadar laicii sunt cei care formează poporul lui Dumnezeu, corpul Bisericii, al cărei cap este Hristos Domnul. Termenul de laic este folosit astăzi în opoziție cu cel de „cleric”, naşte o poziționare exterioară, paralelă, chiar antagonică, între membrii Bisericii: clerici şi laici, poziționare care nu este proprie eclesiologiei ortodoxe. Laicul nu poate fi aşezat alături sau separat de preot şi episcop, ci numai împreună cu aceştia, întrucât numai împreună - clerici şi laiciformează Biserica lui Hristos (IPS Teofan, 2014).

Utilizarea termenului laic, s-a răspândit şi s-a generalizat în cursul primelor trei secole. Dar acei laici nu sunt cei pe care îi cunoaştem noi astăzi. 
Departe de a reprezenta totalitatea tuturor creştinilor, în textele precreştine, laic era, în funcție de context, sinonim cu „simplu”, „aparţinând comunității”, „indigen”, „parte din public”, „comunal”. În revizuirile ulterioare ale textului Septuagintei, apare cuvântul laic, aplicat nu persoanelor, ci lucrurilor, un obiect laic fiind de exemplu opusul unuia sacru, consacrat. Mai târziu laicii constituia o elită: erau acei credincioşi care erau botezați, de sex masculin, bărbaţi ai unei singure femei (Preda, 2008, pp. 274-285).

\section{I.3. Inţelesul termenului de laicism}

Un alt termen care merită anumite precizări este cel de „laicism”. Acesta se referă la acțiunea unor grupuri sau a unui Stat care intenționează să lupte împotriva puterii tradiţiilor religioase din viaţa socială sau politică. Definiţia mai cunoscută a laicismului este aceea de doctrină sau de ideologie care tinde a face din laicitate o luptă împotriva pretențiilor Bisericilor de a guverna viaţa publică. Laicismul presupune fără nici o îndoială că Biserica şi Statul sunt separate, dar fără o perspectivă conflictuală. Laicismul este o ideologie care urmează aceleaşi forme de dogmatism religios. Îl găsim astăzi la mişcările militante care doresc să şteargă orice semn religios din spaţiul public. O altă definiție a laicismului a fost fixată de Academia franceză în anul 1842. Este o doctrină care recunoaşte dreptul laicilor de a guverna Biserica. Noi vom sublinia că termenul laic desemnează cel care nu a primit hirotonia. Prin aceasta Academia franceză a permis să includă şi cazul britanic unde Suveranul cu toate că nu este un cleric este totuşi capul Bisericii Anglicane şi exercită influenţă în cadrul ei. Laicismul desemnează aici extinderea puterii laicilor în puterea religioasă.

\section{Secularizare - laicizare - laicitate}

\section{II.1. Notiunea de secularizare}

In limbajul teologic actual, noțiunea de secularizare apare din ce în ce mai des, însă ea poartă pecetea unei ambiguități semantice. Etimologic, această noțiune vine din limba latină, de la substantivul „saeculum”, care în limba română se poate traduce prin „lume” ca realitate spațio-temporală. În limba latină există şi un alt termen, care exprimă noţiunea de lume, şi anume „mundus”. Acesta, însă, se referă doar la sensul spațial al „lumii”, fiind corespondentul substantivului "cosmos" din limba greacă. Noțiunea de secularizare, derivată din substantivul "saeculum" a avut inițial o conotație 
juridic-canonică, semnificând trecerea unei persoane de la statutul de cleric la statutul de laic sau trecerea bunurilor bisericești din proprietatea Bisericii în proprietatea Statului (Lefebre, 1922, p. 1218).

\section{II.2. Principiile laicității și relația laicizare- secularizare}

Micheline Millot a definit conceptul de laicitate prin obiectivele sale şi anume: „egalitatea şi libertatea de conştiinţă, şi modurile în care se asigură implementarea neutralităţii şi separarea" (Baubérot, Millot, 2011). Sociologul din Quebec, crede că relația dintre aceste principii ajută la o analiză mai corectă a realităţii empirice a laicităţii şi a problemelor istorice şi actuale şi a analizei comparative între diferitele concepții naţionale. Ea insistă asupra necesităţii de a extrage conceptul de laicitate din contextul său francez, a apariției istorice, pentru a elibera de utilizarea sa ideologică şi gândind mai bine ca la un concept politic. Laicitatea reprezintă după ea, „dezvoltarea politică, apoi traducerea juridică, de la locul religiei în societatea civilă şi în instituțiile publice" (Millot, 2002, p. 56). Plecând de la diferitele contexte istorice şi politice, Millot elaborează o diagramă (schemă) a laicității cu şase tipuri ideale: laicitate separatistă (Mexic, Franța, Japonia etc), laicitate anticlericală (Uruguay, Coreea de Nord, China etc), laicitate autoritară (Turcia, Tunisia, etc ), laicitate de credinţă civică, laicitate de recunoaştere (Canada) şi laicitate de colaborare (România, Germania, Austria etc) (Baubérot, Millot, 2011, p. 89).

Incercând o lămurire mai precisă a noțiunii de laicizare, mai mulți specialişti o compară cu cea de secularizare, prima fiind mai familiară spațiului francofon, iar cea de-a doua spațiului anglofon. Jean Baubéron a propus o distincție clară între noțiunile de laicizare şi secularizare, arătând că dacă laicizarea presupune un conflict sau o separare evidentă între Stat şi Biserică sau între Stat şi religie, secularizarea se referă la o pierdere progresivă din partea Bisericii a rolului şi influenței religiei în plan social, în societate, o separare a valorilor religioase şi bisericeşti de planul social (Bauberot, 1994, p. 12). După el, definiția cea mai des utilizată - „reducerea laicităţii la un singur parametru: un regim de separare între Stat şi religii” (Baubérot, Millot, 2011, p. 7).

Pentru a rezolva această problemă de traducere, Jean-Paul Willaime propune pentru să traducă laicitate prin secularism în engleza, păstrând cele trei elemente care în opinia sa se bazează laicitatea:

- Libertatea de conştiință, de gândire şi de religie care include libertatea de avea sau de a nu avea o religie, libertatea de a schimba religia şi de a participa sau nu la religia pe care a ales-o. 
- Drepturile si obligațiile cetățenilor indiferent de apartenența lor religioasă sau filosofică.

- Autonomia, respectiv, statul şi religiile (Willaime, 2008).

Plecând de la această înțelegere, profesorul Jean Paul Willaime susține că la nivel european s-a dezvoltat din ce în ce mai mult o „recunoaştere a laicităţii şi a dialogului” (Willaime, 2011).

Mult timp a fost considerat că laicitatea este un cuvânt intraductibil, atât din punct de vedere lingvistic cât şi semantic, în alte limbi decât cea franceză (Millot, 2002, p. 12). Cu toate acestea, în toate limbile, neologismele şi împrumuturile lingvistice abundă. Neologismul laitcy, îl regăsim după ceva timp în scrierile ştiințifice engleze, şi în limba spaniolă care utilizează cuvântul laicidad, în italiană laicita. Curtea Europeană a Drepturilor Omului în hotărârile şi în documentele internaționale traduce în engleză, termenul de laicitate prin secularism şi Stat laic prin Stat secular. Recent neologismul laicitate este folosit în textele academice. Cu toate acestea, mulți dintre francezi cred ca laicitatea este o „excepție franceză” şi se reuşeşte adesea ca această credinţă să fie împărtăşită şi de numeroase persoane din diferite țări (Bauberot, 2007, p. 26).

\section{Laicitatea în România}

Înainte însă de căderea regimului comunist, pe parcursul secolului al XX-lea, în România relația Biserică - Stat se situează în o logică a laicității Statului, având două tipuri de laicitate: laicitate autoritară şi laicitate anticlericală. Specificul ortodoxiei bizantine în ceea ce priveşte relația Biserică- Stat, putem vorbi despre o simfonie a puterilor între religie şi politică, moştenită de Biserica ortodoxă, influențată de societatea română (Tanase, 2008). Comparativ cu istoria Occidentului, relația religie - politică este marcată de o atmosferă de dialog şi cooperare, în țările majoritar ortodoxe din Europa de Est. Cu toate că tensiunea a existat în această parte a Europei, în istoria poporului român „, Biserica Ortodoxă nu a fost niciodată un rival al Statului” (IPS Daniel, 2005, p. 13). În perioada interbelică, asistăm la o clericalizare a vieții eclesiale, adică la o dorinţă a ierarhiei de a se impune în toate planurile. $\mathrm{Nu}$ trebuie să uitam faptul că toți episcopii recunoscuți din Regatul României, indiferent de confesiune, făceau parte automat din senat, erau senatori de drept şi pe viată. Trebuie amintit aici şi de faptul că patriarhul Miron Cristea a fost numit pentru o perioada senator, regent (1927-1930) şi în cel din urmă al vieții a deținut funcția de prin-ministru (1938-13939). Datorită acestui fapt, gurile rele din acea perioada spuneau că Miron Cristea 
este prim-ministru la Patriarhie şi patriarh la Guvern. Paradoxul perioadei interbelice este că în timp ce laicii erau apărătorii duhului bisericesc, ierarhia se auto seculariza.

După 1989 relația Biserică - Stat este o relaţie de parteneriat şi cooperare între instituțiile publice şi cele religioase. Din punct de vedere juridic, pe teritoriul României avem de a face cu o laicitate de cooperare, în conformitate cu schema propusă de Baubérot şi Millot.

Victor Opaschi, actualul ministru al Secretariatului de Stat pentru culte, nu consideră relația Stat - Biserica Ortodoxă ca fiind una privilegiată, ci o relație care prezintă o realitate concretă. Biserica Ortodoxă Română primeşte cea mai mare parte a subvențiilor destinate cultului, nu pentru că este privilegiată, ci pentru că este majoritară (Popa, 2013). Legea 489/2006 asupra libertății religioase şi regimul general al cultelor, fixează aspectele şi reprezintă cadrul juridic a vieții religiase în România. Secretariatul de Stat pentru Culte are o rolul de mediator a vieții religioase, o funcție juridico - economică în peisajul religios român. Este instituția care face legătura între instituțiile publice si cele religioase. În cele din urmă vedem preocuparea statului român pentru viaţa religioasă prin însăsi existenţa unei astfel de institutii. Legea 489/206 asupra libertăţii religioase şi regimul general al cultelor, reaminteşte de dreptul constituţional al religiilor, stabileşte principiile de bază în acest domeniu şi stabileşte procedurile de organizare şi susținere a cultelor.

\section{REFERENCES}

Bauberot, J., \& Millot, M. (2011). Laïcités sans frontières. Paris: Ed. du Seuil. Bauberot, J. (1994). Religions et laïcité dans l'Europe des Douze. Paris: Ed. Syros. Bauberot, J. (2007). Les laïcités dans le monde. Paris: Ed. PUF.

Faivre, A. (2007). Les laics aux origines de l'Eglise. Paris: Ed. du Cerf.

Popa, E. (2013). „Statul român nu este un stat laic”, susține secretarul de stat Victor Opaschi. In Jumalul.ro. Available online at: http://jurnalul.ro/special-jurnalul/interviuri/statul-roman-nu-esteun-stat-laic-sustine-secretarul-de-stat-victor-opaschi-644477.html

IPS Teofan, Mitropolitul Moldovei şi Bucovinei. (2014). „Preoția împărătească - Slujirea laicilor în Biserică”. În Pr. Vicovan I şi Roman E., Laicii şi misiunea cresstină, realitate istorică, vocatie personală şi necesitate eclesială, Colecția Episteme, (pp. 74 -79). Iaşi: Ed. Doxologia. 
IPS. Daniel, Mitropolitul Moldovei şi Bucovinei. (2005). Relațiile Stat-Biserică in România. Tradiție și actualitate, „Libertatea religiaosă in context românesc şi European”. Bucureşti: Ed. Bizantină.

Lacoste, J. Y. (2007). Dictionaire critique de Théologie. Paris: Nouvelle édition revue et augmentée septembres, Presses Universitaire de France.

Lefebre, S. (1922). „Secularité”. In René L. \& Rino F., Dictionnaire de Théologie fondamentale, sous la direction de, Editions Bellarmin. Paris: Ed. du Cerf.

Millot, M. (2002). La laïcité dans le nouveau monde. Le cas du Québec, Brepols: Ed. Turnhout.

Millot, M. (2008). La lä̈cité. Montréal: Ed. Novalis.

Preda, R. (2008). „Laicatul ortodox din România postcomunistă. Un portret social-teologic". In Ioan Chirilă, Cristian Bârsu (coord.), Un neobosit slujitor al Bisericii: Preasfinţitul Episcop-Vicar Vasile Someşanul, Cluj-Napoca: Ed. Renaşterea.

Tănase, L. (2008). Pluralisation religieuse et société en Roumanie. Bern: Ed. Peter Lang.

Willaime, J. P. (2008). Le retour du religieux dans la sphère publique. Vers une laïcité de reconnaissance et de dialogue. Paris: Ed. Olivétan.

Willaime, J. P. (2011). Les évolutions en Europe. Vers une laïcité de reconnaissance et de dialogue. In actele Simpozionului internațional pe interculturalitate, 25-27 mai, Montreal, 2011, available online at: www.symposium-interculturalisme.com.

www.culte.gov.ro/.

\section{Acknowledgement}

Această lucrare a fost sprijinită financiar în cadrul proiectului POSDRU/187/1.5/S/155397 cu titlul „Prin burse doctorale spre o nouă generație de cercetători de elită", cofinanţată din Fondul Social European prin intermediul Programului Operațional Sectorial Dezvoltarea Resurselor Umane 2007-2013. 


\section{Biodata}

\section{PhD Andrei POPÎRDA}

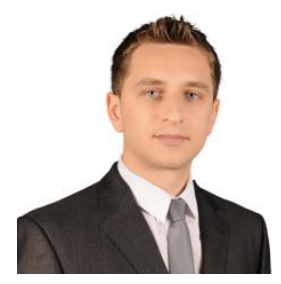

Born in 17.07.1988 in Piatra Neamt (Romania).

Between 2008-2012 I made Faculty of Orthodox Theology „Dumitru Stăniloae”, followed by Master degree program „Teologie sistematică în context contemporan". In 2014, I enrollated in Phd. program, in the same Faculty, in Ethic Theology, having as supervisor on Father Prof. PhD. Gheorghe POPA. Between January - June 2013, scholarship at University of Strasbourg (France). I have participated at International Symposium „Studia Theologica Doctoralia”, in 12-15 may 2015, were I presented the article „Responsabilitatea misionară a laicilor în parohie".

Popirda, A. (2015). The Concept of Secularism in Theological and Political Perspective. Logos Universality Mentality Education Novelty, Section: Philosophy and Humanistic Sciences, III (2), 57-65. Doi: http://dx.doi.org/10.18662/lumenphs.2015.0302.05 